\title{
Information Model of the Computer-Integrated Technology for Wireless Monitoring of the State of Microclimate of Industrial Agricultural Greenhouses
}

\author{
Ivan S. Laktionov ${ }^{1 *}$, Oleksandr V. Vovna ${ }^{2}$, Maryna M. Kabanets ${ }^{3}$, Hanna O. Sheina ${ }^{2}$, Iryna A. Getman ${ }^{4}$ \\ ${ }^{1}$ Department of Automation and Telecommunications, Faculty of Computer-Information Technologies and Automatization, \\ SHEE 'Donetsk National Technical University' of the Ministry of Education and Science of Ukraine, Shybankova sq., 2, Pokrovsk \\ UA85300, Ukraine \\ ${ }^{2}$ Department of Electronic Engineering, Faculty of Computer-Information Technologies and Automatization, SHEE 'Donetsk \\ National Technical University' of the Ministry of Education and Science of Ukraine, Shybankova sq., 2, Pokrovsk UA85300, \\ Ukraine \\ ${ }^{3}$ Language Training Department, Faculty of Economics and Management, SHEE 'Donetsk National Technical University' of the \\ Ministry of Education and Science of Ukraine, Shybankova sq., 2, Pokrovsk UA85300, Ukraine \\ ${ }^{4}$ Department of Computer and Information Technology, Donbass State Engineering Academy of the Ministry of Education and \\ Science of Ukraine, Akademichna st., 72, Kramatorsk UA84313, Ukraine
}

Corresponding Author Email: ivan.laktionov@ donntu.edu.ua

https://doi.org/10.18280/i2m.200601

Received: 26 October 2021

Accepted: 4 December 2021

\section{Keywords:}

uncertainty, transfer, aggregation, model, information, observation, measurement, greenhouse

\begin{abstract}
Currently, computer-integrated technologies are increasingly used, which leads to a continuous search for scientifically grounded ways of their development. Agriculture is one of such industries, whose needs require urgent modernization by introducing modern computer, sensor and infocommunication technologies. The purpose of the article is to develop scientific and applied foundations for improving computer-integrated systems for monitoring the state of the microclimate of agricultural greenhouses through the synthesis of an information model of the process of wireless exchange of observation results of physical and chemical parameters. Basic research methods: critical analysis and logical generalization; information and computer modelling; synthesis of structural and algorithmic organizations of computer-integrated technologies; probability theory; the concept of the Internet of Things; experimental testing of computer-integrated and infocommunication equipment. The scientific novelty of the results lies in the development of a method for network aggregation of measurement information, which, unlike the known ones, implements algorithms for detection and software elimination of typical errors in the operation of the system functional modules, which made it possible to reduce the likelihood of uncertainties in the measurement results from $0.6 \%$ to $0.01 \%$ during network transformation of information. The practical value of the results lies in the development and implementation of a software information model of local and remote aggregation, processing and visualization of the results of observations of the dynamics of the greenhouse microclimate parameters based on the concept of the Internet of Things.
\end{abstract}

\section{INTRODUCTION}

\subsection{Relevance of the research topic}

At present, computer-integrated technologies are increasingly used, which leads to a continuous search for scientifically sound ways of their development. One of such industries, whose needs require urgent modernization through the introduction of modern computer, sensor and infocommunication technologies, is agriculture. Today, one of the most important industries in terms of food security and year-round availability of quality food is greenhouse vegetable growing. This fact is confirmed by the dynamic growth of greenhouse areas in the world. According to the international organization FAO, over the past ten years, this figure has increased by about $25 \%$ and, according to experts, in 2020 amounts to 498 thousand hectares [1].

During cultivation of crops, industrial agricultural greenhouses should be considered as objects of continuous operation with a certain working space, the characteristics of which are determined by the set of soil and climatic parameters of the microclimate and irrigation solution. Factors of spatial heterogeneity of physical properties and processes during greenhouse cultivation, the relationship of regulated to the measurement monitoring of physical parameters of the microclimate and the scale of measurements have not allowed creating computer-integrated technologies that meet the requirements for systemic and complex primary and secondary transformations of information by computerized means in the conditions of industrial greenhouses with the regulated worldrecognized norms of $\mathrm{FAO}$ and ASABE concerning metrological and functional maintenance $[2,3]$.

Due to the fact that most sensors of such systems operate in real time and are in an aggressive environment (soil, air with high humidity or irrigation solution) and are spatially separated, there is a relevance and need to develop computerintegrated technology for monitoring the integrated state of the greenhouse microclimate by wireless sensor network. 


\subsection{Bibliographic review, critical analysis and logical generalization of known scientific results}

In order to effectively control the productivity of greenhouse crops, it is necessary to perform continuous nondestructive measurement monitoring of a significant number of soil parameters, air-gas and irrigation solution, because without this it is impossible to determine the integrated state of the microclimate and generate signals of adaptive adjustment of technological processes in greenhouses [4-7].

This scientific and applied problem can be solved by expanding the functionality of classical information and measurement systems through the introduction of modern methodological approaches to the Internet of Things and wireless sensor networks, as well as methods of intelligent analysis of physical quantities, which is proven and tested in articles [8-10].

In research articles [11-13] the authors found that during the development and implementation of computer-integrated technologies for wireless monitoring of microclimate parameters during the technological processes of growing crops in greenhouses, the following modern infocommunication technologies are used: Wireless ZigBee 2.4 GHz, Wireless Wi-Fi, Wired Modbus, Wireless Ethernet, GPRS and Wireless LORA-CBF. In the article [14] it was determined that at present the modern component base allows synthesizing the architecture of the wireless sensor network according to the following criteria: Maximum energy efficiency, minimum time delay and adaptive traffic. Jørgensen [15] formulates the basic requirements for technical systems of precision farming within the concept of "Industry 4.0" and "Agriculture 4.0", which allows synthesizing a number of requirements for infocommunication provision of contemporary systems for monitoring and control of technological processes of growing crops. The scientific and practical aspects of development, testing and implementation of computerized wireless monitoring systems based on serial hardware and software components are presented [16, 17].

Details of the general trends in the use of modern infocommunication, microprocessor and sensor technologies during the implementation of certain procedures of nondestructive measurements and intellectual control of the microclimate of greenhouses are given in Table 1 .
During the logical generalization of the known results of scientific research and applied developments in the field of computer-integrated technologies for monitoring the microclimate parameters of industrial greenhouses [18-24] it was established that most of them are devoted to the development of hardware and software solutions for individual parameters. Despite the qualitative solution of certain problems of software and hardware development of computerized systems, the theory of complex monitoring of the state of the analyzed physical environments is in the process of formation. Thus, the main issues that need further development during the investigation and development of the information model of computer-integrated technology for wireless monitoring of the industrial greenhouse microclimate based on the known theories are: accounting for principles of consistency and complexity of collecting and processing distributed measurement information; deepening of theoretical bases of sensor location substantiation and the account of interrelations of the measured parameters during interpretation of an integral environment condition.

\subsection{Purpose, object, subject and structure of the research}

The main purpose of the article is to develop scientific and applied bases for improving computer-integrated systems for monitoring the microclimate of industrial agricultural greenhouses by synthesizing an information model of wireless exchange of observations of physical and chemical parameters, which will increase the efficiency of greenhouse cultivation. The research object is non-stationary processes of aggregation of measurement information on the integrated state of the greenhouse microclimate. The research subject is methods and tools of computer-integrated infocommunication monitoring of the greenhouse microclimate.

The structure of the article: section 1 contains information on the relevance and current state of the subject area; section 2 provides information on the materials and methods used during the development of the information model of the studied technology; in section 3 the main quantitative and qualitative results of modeling of the studied technology are presented and analyzed; section 4 substantiates the priority areas for further research; section 5 presents the main conclusions of the article.

Table 1. Results of the use of information technology in monitoring the parameters of agricultural production

\begin{tabular}{|c|c|c|c|c|}
\hline Hardware components & $\begin{array}{c}\text { Controlled technological } \\
\text { processes }\end{array}$ & $\begin{array}{c}\text { Data transmission } \\
\text { technology }\end{array}$ & Results & $\begin{array}{l}\text { Source } \\
\text { number }\end{array}$ \\
\hline $\begin{array}{c}\text { Sensors: humidity and air temperature, } \\
\text { soil moisture. Microcontroller: Arduino } \\
\text { Uno }\end{array}$ & $\begin{array}{l}\text { ventilation, heating, drip } \\
\text { irrigation }\end{array}$ & wired & $\begin{array}{l}\text { reduction of the human factor, } \\
\text { reduction of used water resources, } \\
\text { increase of productivity. }\end{array}$ & [18] \\
\hline $\begin{array}{l}\text { Sensors: humidity and air temperature, } \\
\text { soil moisture, soil acidity, light intensity }\end{array}$ & $\begin{array}{l}\text { artificial lighting, soil } \\
\text { irrigation }\end{array}$ & $\begin{array}{l}\text { no information } \\
\text { available }\end{array}$ & $\begin{array}{l}\text { reduction of the human factor, } \\
\text { reduction of used water resources. }\end{array}$ & [19] \\
\hline $\begin{array}{l}\text { Sensors: soil moisture, soil acidity. } \\
\text { Microcontroller: ARM9 }\end{array}$ & drip irrigation & wireless & $\begin{array}{l}\text { optimization of fertilizer } \\
\text { application to irrigation solution } \\
\text { during drip irrigation. }\end{array}$ & {$[20]$} \\
\hline $\begin{array}{c}\text { Sensors: humidity and air temperature, } \\
\text { light intensity }\end{array}$ & soil irrigation & wireless & $\begin{array}{c}\text { the use of wireless technology in } \\
\text { large greenhouses can lead to } \\
\text { measurement uncertainty. }\end{array}$ & {$[21]$} \\
\hline $\begin{array}{c}\text { Sensors: soil moisture. } \\
\text { Microcontroller: ATMEGA } 16\end{array}$ & soil irrigation & wireless & $\begin{array}{l}\text { reduction of the human factor, } \\
\text { reduction of used water resources. }\end{array}$ & {$[22]$} \\
\hline $\begin{array}{l}\text { Sensors: humidity and air temperature, } \\
\text { soil moisture and acidity, light intensity }\end{array}$ & $\begin{array}{l}\text { heating, artificial lighting, } \\
\text { soil irrigation }\end{array}$ & wired & no information available. & {$[23]$} \\
\hline $\begin{array}{c}\text { Sensors: humidity and air temperature, } \\
\text { Microcontroller: ATmega 16A }\end{array}$ & drip irrigation & wired and wireless & no information available. & {$[24]$} \\
\hline
\end{tabular}




\subsection{Scientific novelty and practical value of the obtained results}

The scientific novelty of the results lies in the development of a method for network aggregation of measurement information, which, unlike the known ones, implements algorithms for detection and software elimination of typical errors in the functional modules of the system, which reduced the probability of uncertainties in measurement results from $0.6 \%$ to $0.01 \%$ during network information transformation. The practical value of the results lies in the development and implementation of a software information model of local and remote aggregation, processing and visualization of the observation results of the greenhouse microclimate dynamics based on the concept of Internet of Things.

\section{MATERIALS, TOOLS AND METHODS}

\subsection{Basic research methods}

The theoretical basis for solving the scientific and applied problem and achieving the set goals is an integrated approach using: methods of critical analysis and logical generalization; methods of information and computer modeling; methods of synthesis of structural and algorithmic organizations of computer-integrated technologies; probability theory and mathematical statistics; Internet of Things concepts; methods of computer analysis of measurement results; approaches to experimental testing of computer-integrated and infocommunication equipment.

The main results of the experimental research were obtained in specialized laboratories "Computer Technology and Modeling" and "Information and Measurement Technology and Metrology" of SHEI "Donetsk National Technical University" using standardized and certified equipment and licensed software.

\subsection{Structural and algorithmic organization of the investigated computer-integrated technology}

As the main method of substantiation of the structural and algorithmic organization of the investigated computer- integrated technology of wireless monitoring of greenhouse microclimate, the structural technique of algorithmization on the basis of the principle of decomposition of a research problem on subtasks is used. Taking into account the results of the previous studies, which are presented in Section 1 of the article, a generalized architecture (see Figure 1) and a block diagram of the operation algorithm (see Figure 2) of the studied technology for monitoring the greenhouse microclimate was developed.

In Figure 1, the following notation is introduced: $W_{a c t}^{\text {ai in }}-$ result of instrumental monitoring of humidity in the growing area, $\%$; $v_{a c t}^{\text {air in }}$-result of instrumental monitoring of air flow rate in the growing area, $\mathrm{m} \cdot \mathrm{s}^{-1} ; T_{a c t}^{\text {air in }}$-result of instrumental monitoring of air temperature in the growing area, ${ }^{\circ} \mathrm{C} ; C_{a c t}^{C O 2}$ in -result of instrumental monitoring of carbon dioxide concentration in the growing area, ppm; $E_{a c t}^{e \text { in }}$-result of instrumental monitoring of energy illumination in the greenhouse growing zone, $\mathrm{W} \cdot \mathrm{m}^{-2} ; T_{a c t}^{\text {soil }}$ - result of instrumental monitoring of soil temperature, ${ }^{\circ} \mathrm{C} ; W_{\text {act }}^{\text {soil }}$-result of instrumental monitoring of soil moisture, \%; $O P R_{a c t}^{\text {water }}$-result of instrumental monitoring of the redox potential of the irrigation solution, $\mathrm{mV} ; p H_{\text {act }}^{\text {water }}$-result of instrumental monitoring of irrigation solution acidity, units; $E C_{a c t}^{\text {water }}$-result of instrumental monitoring of electrical conductivity of the irrigation solution, $\mathrm{Cm} \cdot \mathrm{cm}^{-1} ; T_{\text {act }}^{\text {water }}$-result of instrumental monitoring of irrigation solution temperature, ${ }^{\circ} \mathrm{C} ; W_{\text {act }}^{\text {air out }}$ result of instrumental monitoring of ambient humidity, \%; $D_{\text {act }}^{\text {air out }}$-result of instrumental monitoring of air direction in the environment; $v_{\text {act }}^{\text {air out }}$-result of instrumental monitoring of air flow speed in the environment, $\mathrm{m} \cdot \mathrm{s}^{-1} ; T_{\text {act }}^{\text {air out }}$-result of instrumental monitoring of ambient air temperature, ${ }^{\circ} \mathrm{C}$; $C_{\text {act }}^{\mathrm{CO} 2 \text { out }}$-result of instrumental monitoring of carbon dioxide concentration in the environment, $\mathrm{ppm} ; E_{\text {act }}^{\text {e out }}$-result of instrumental monitoring of illumination in the environment, $\mathrm{W} \cdot \mathrm{m}^{-2}$.

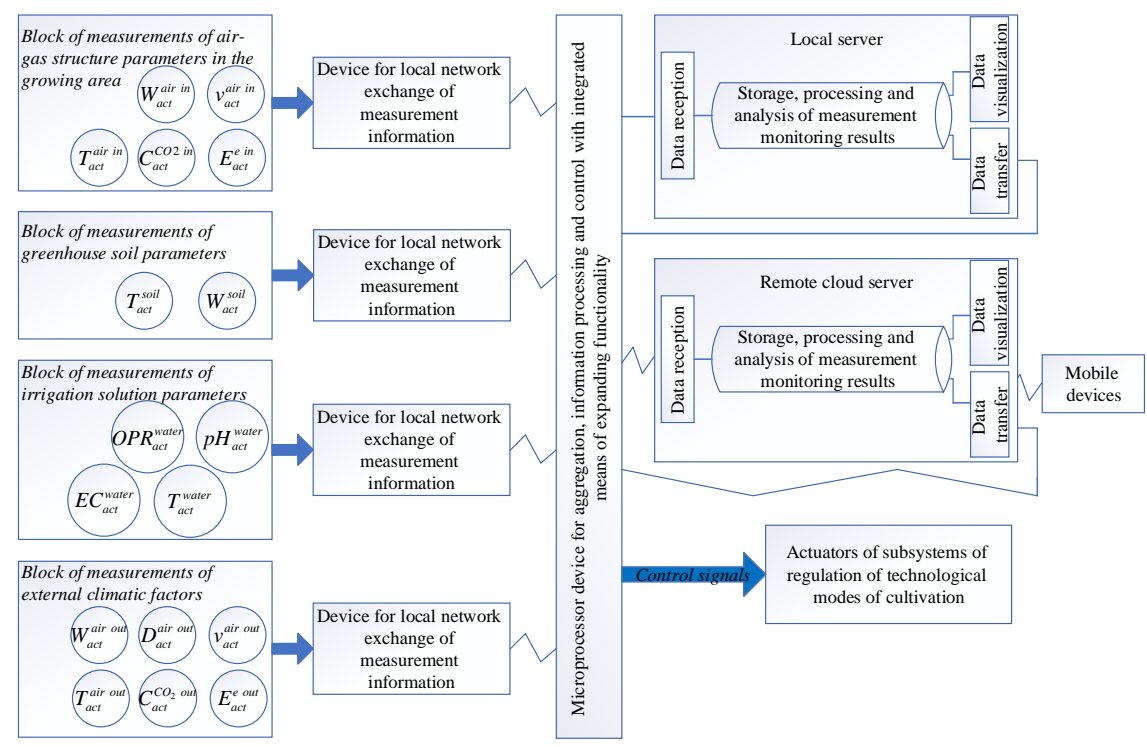

Figure 1. Generalized architecture of the studied technology of greenhouse microclimate monitoring 


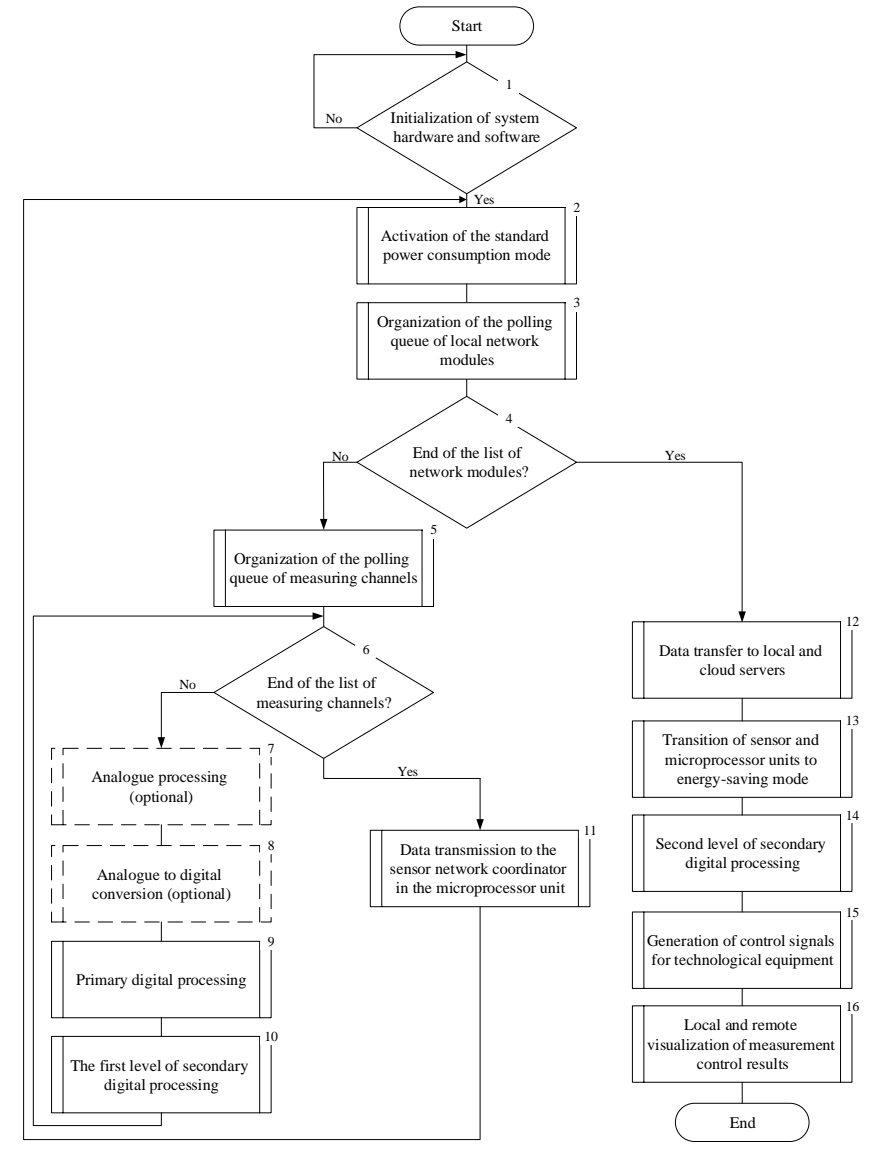

Figure 2. Block diagram of the algorithm of the investigated technology of greenhouse microclimate monitoring

The proposed structural and algorithmic organization of computer-integrated technology for greenhouse microclimate monitoring meets the current requirements for: Efficiency, accuracy and systematization of transformation and reliability of measurement information transmission; adaptability and ergonomics of user functionality; integration of intelligent algorithms for self-diagnosis of results during aggregation, transmission and processing of measured data.
The obtained results form a theoretical basis for designing a prototype of a computer-integrated system for monitoring the state of the greenhouse microclimate, which, in turn, is designed to test information models of wireless exchange of measurement observations on the dynamics of informative parameters and destabilizing factors of the integrated state of the microclimate.

\subsection{Software and hardware tools of the investigated computer-integrated technology}

A functional diagram of the implemented prototype of the computer-integrated system for greenhouse microclimate monitoring is shown in Figure 3.

The proposed structure is modular and performs the following list of basic functions: Measurement of the regulated list of microclimate parameters; analogue-to-digital conversion of sensor output signals; accumulation of a database of observation results; local and remote interpretation and indication of results; generating signals that control the modules to support technological processes.

To implement the system (see Figure 4), serial budget models of sensors and expansion boards were used, which are compatible at the algorithmic and circuitry levels with the Arduino Mega 2520 microprocessor platform, as shown in Figure 3. Most of the used sensors have analog type of connection. Also, some sensors use standard protocols such as I2C and 1-Wire. The relay unit is connected using the digital ports of Arduino. The SPI and UART protocols are used to connect expansion cards (GSM / GPRS modem and Flash drive). All components are powered via the $5 \mathrm{~V}$ DC line, except the GSM / GPRS module, which is powered via the $12 \mathrm{~V} \mathrm{DC}$.

The software tools that were used in the design of the prototype of the computer-integrated technology are as follows: Arduino IDE, MS Excal, MathCAD, CupCarbon IoT Simulator and Thing Speak IoT Analytics. The functional purpose of each of the software used is shown in Figure 5. During the research, the described software components have been used sequentially, as shown in Figure 5.

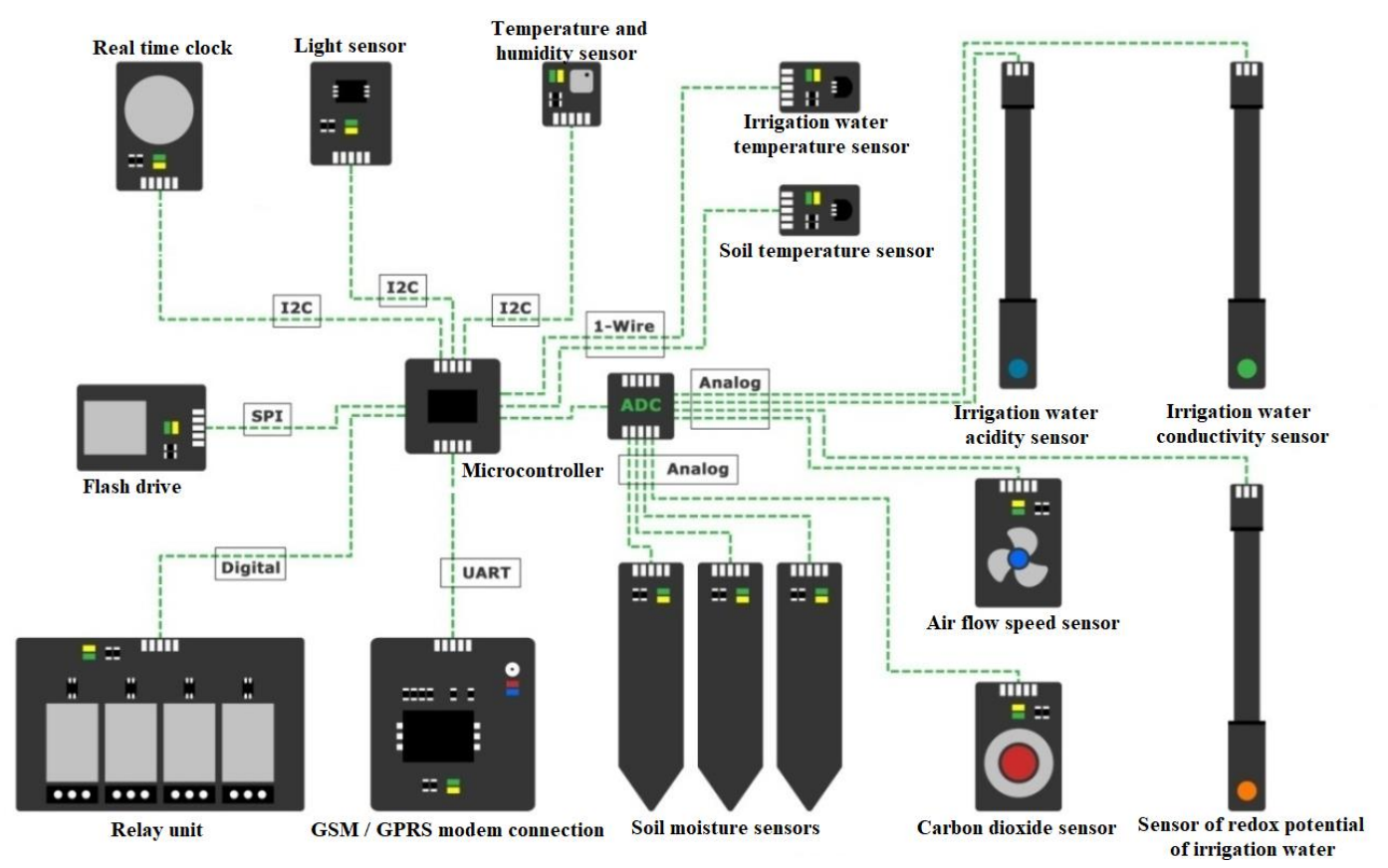

Figure 3. Functional diagram of the experimental sample of the system for greenhouse microclimate monitoring 


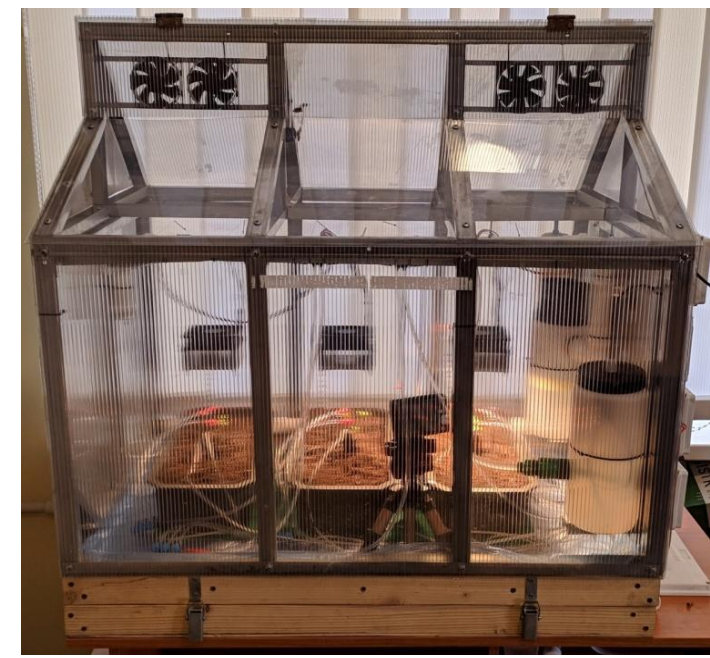

a) General view of the computerized greenhouse prototype (The dimensions of the implemented physical model of the greenhouse are the following: height- $1.5 \mathrm{~m}$, length of base$1.5 \mathrm{~m}$, width of base $-0.9 \mathrm{~m}$ )

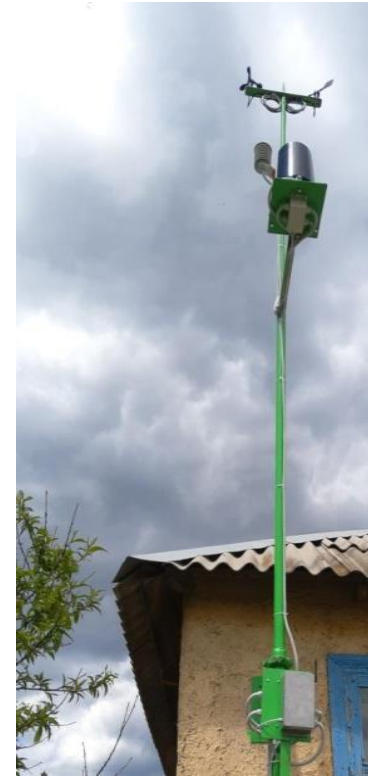

b) Unit for monitoring external climatic parameters

Figure 4. Prototypes of the computer-integrated means of monitoring the state of the greenhouse microclimate

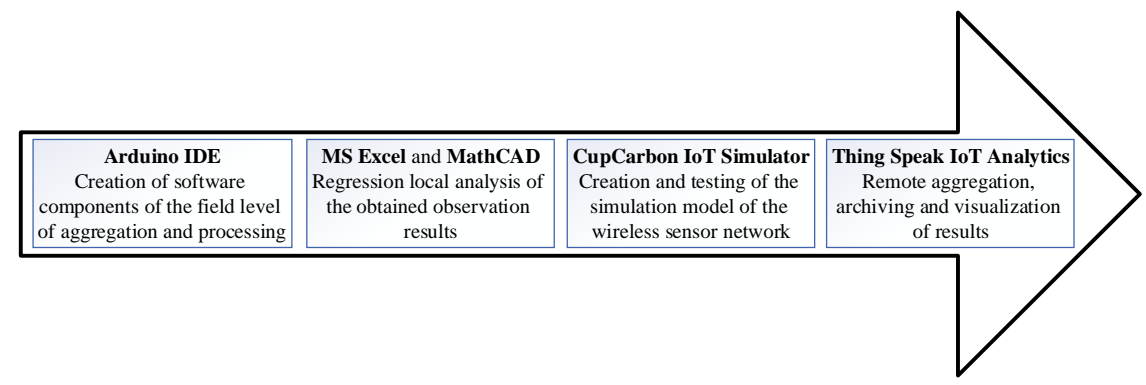

Figure 5. Structure of the software use of the studied computer-integrated monitoring technology

Taking into account the characteristics of the hardware and software components used in the design of the computerized greenhouse prototype and the unit for monitoring external climatic factors, it can be stated that the development meets the basic scientific and practical provisions of IoT and WSN technologies and can be used as software and hardware base in researching information models of wireless monitoring of the integrated state of the microclimate of industrial agricultural greenhouses.

\section{RESEARCH RESULTS}

\subsection{Simulation modelling of the process of wireless exchange of measurement information}

Functional nodes of sensors and wireless information exchange of the studied computer-integrated technology were synthesized by the criterion of maximum energy efficiency due to a significant number of sensors and wireless modules that cause a significant current of up to $800 \mathrm{~mA}$ (in active operation mode) and up to $300 \mathrm{~mA}$ (in standby operation mode). During the implementation of this development stage, an algorithm for energy-efficient scheduling of transitions of sensors and data transmission modules from standby to active mode was used [25], which allows optimizing the number of such transitions and reducing synchronization time between network structural modules (see Figure 6). The wireless modules turn on in active mode only when sending packets of measurement results by software methods (more details at the bottom of Figure 6). During implementation of this approach, sensors for monitoring the air-gas and soil-climatic condition of the growing area are grouped and connected to wireless modules, network terminals (ZED).

The number of such groups of sensors and modules depends on the area of industrial greenhouses and is selected by the condition: one group per $100 \mathrm{~m}^{2}$ by five-point technology (in the centre and vertices of the square). Next, information from each group of sensors is transmitted to a routing device (ZR), which performs the function of retransmitting the information to the coordinating device (ZC). Similarly, the procedures of information aggregation and transmission from groups of sensors of external climatic parameters and characteristics of the irrigation solution are performed.

Based on the proposed structural and functional organization of the sensor network, a simulation model of the system was developed and tested in the IoT Wireless Sensor Network Simulator CupCarbon environment, as shown in Figure 7. This allowed us to investigate the operation modes of the system and to make requirements to clarify the number and topology of the sensors. In order to clarify the locations of sensors and the number of wireless modules, calculations of the main indicators of the coverage area were performed using the method of multimetric wireless measurements [26]. According to the recommended monitoring method for agricultural conditions, groups of sensors and functional devices for wireless information exchange are placed in the vertices and the centre of the square, as shown in Figure 8. 


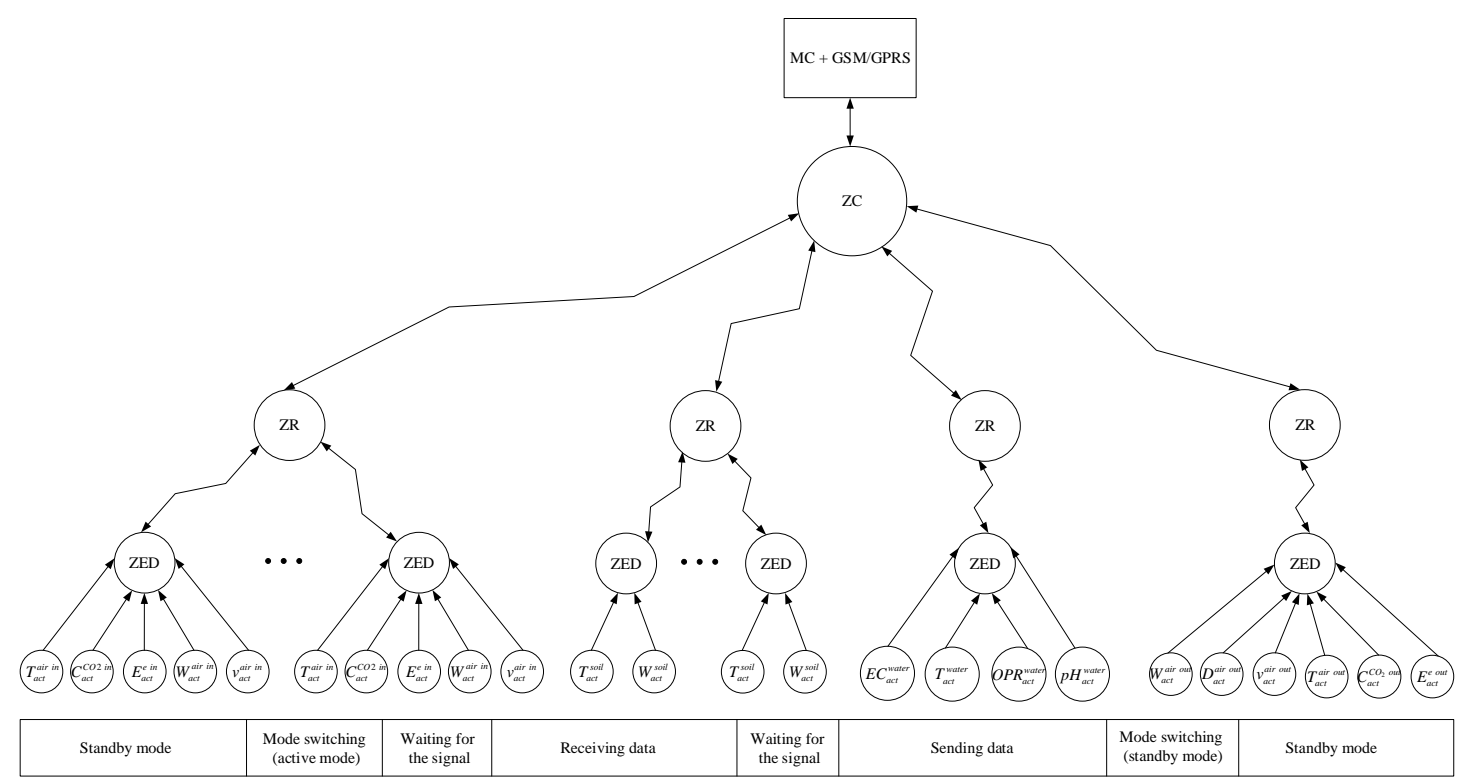

Figure 6. Structural and functional organization of the sensor network for greenhouses

During the substantiation of the number and locations of sensors of greenhouse microclimate parameters in the growing area, the method of multi-purpose optimization was used for five quality indicators of wireless sensor networks [26] according to the formula (1). The optimization task is to find the maximum of the function (1), the arguments of which unambiguously depend on the range of information exchange devices. This task has been solved using a graphical method.

$$
\text { Location }_{\text {opt }}=\max \left(C_{a}^{T}, C_{a}^{E}, C_{a}^{N E}, C_{a}^{T N O}, 1 / C_{a}^{T O}\right)
$$

where, Location $_{\text {opt }}$ - target function of optimizing the placement of groups of sensors and functional modules; $C_{a}^{T}-$ total coverage area, $\mathrm{m}^{2} ; C_{a}^{E}-$ effective coverage area, $\mathrm{m}^{2}$; $C_{a}^{N E}$ - net (covered by only one group) effective coverage area, $\mathrm{m}^{2} ; C_{a}^{T N O}$ - total area of non-overlapping coverage, $\mathrm{m}^{2}$; $C_{a}^{T O}$ - total area of overlapping coverage, $\mathrm{m}^{2}$.

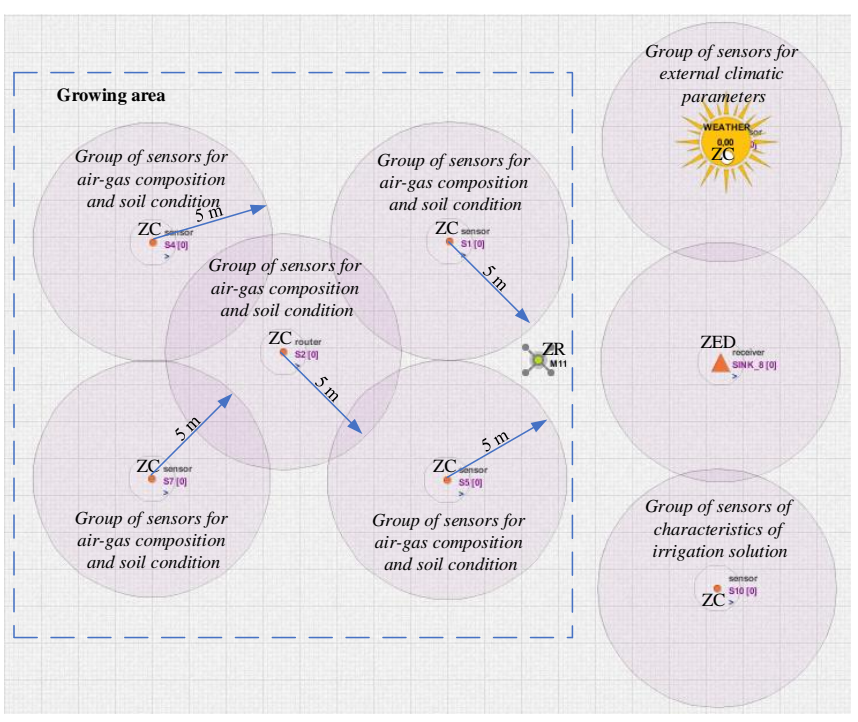

Figure 7. Simulation computer model of the wireless network of sensors for greenhouse conditions

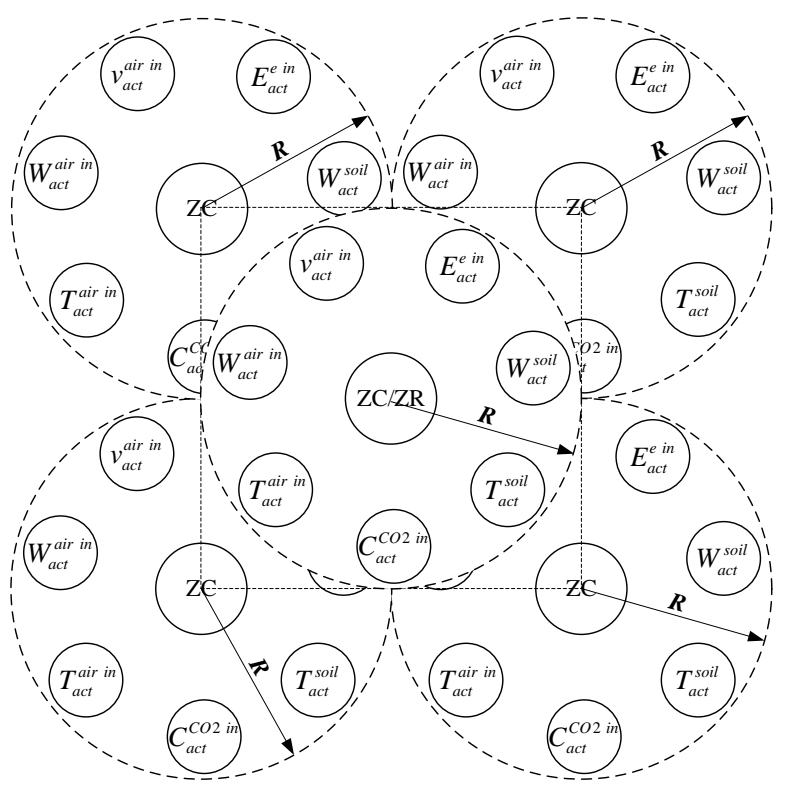

Figure 8. Fragment of the topology of hardware components for monitoring the microclimate state in the growing area

Given the method of constructing a network of sensors at the vertices and the centre of the square, the formulas for calculating the dependence of the quality parameters of the network operation on the range of functional devices are as follows [26]:

$$
\left\{\begin{array}{l}
C_{a}^{T}=\left(\frac{7 \pi}{3}+2 \sqrt{3}+4\right) R_{a c t}^{2} ; \\
C_{a}^{E}=\frac{\left(\frac{7 \pi}{3}+2 \sqrt{3}+4\right) R_{a c t}^{2}}{9 \pi R_{a c t}^{2}}=0,52 ; \\
C_{a}^{N E}=\frac{\pi+6 \sqrt{3}}{12} R_{a c t}^{2} ; \\
C_{a}^{T N O}=3\left(\frac{\pi+6 \sqrt{3}}{4}\right) R_{a c t}^{2} ; \\
C_{a}^{T O}=\left(\frac{19 \pi}{12}-\frac{5 \sqrt{3}}{2}+4\right) R_{a c t}^{2},
\end{array}\right.
$$


where, $R_{a c t}$ - range of information exchange devices, $\mathrm{m}$.

Based on the system of Eq. (2) taking into account the characteristics of serial Xbee modules, which were selected on the basis of the criterion of optimal energy efficiency, we obtained graphical dependences of the parameters of information exchange, which are shown in Figure 9.

Based on the quantitative analysis of the results of modelling the quality of wireless exchange of measurement information in greenhouse conditions (see Figure 9), it was established that function (1) has no extremes. Therefore, solving the problem of multi-purpose optimization is not possible. Based on the analysis of the practical orientation of solving the problem of substantiation of the topology and the number of modules, it was found that the total coverage area under the regulated topology of sensor groups $\left(R_{a c t}=5 \mathrm{~m}\right)$ is $370 \mathrm{~m}^{2}$. A sufficient number of groups of sensors for the characteristics of the irrigation solution and external climatic parameters is equal to one, and the topology of their location is determined by the engineering design of greenhouses.

The final stage of measurement information exchange is its transfer to the remote cloud server of aggregation and analysis of results, and also visualization of results on mobile devices of administrative personnel of industrial greenhouses. Based on the analysis of greenhouse locations (mainly in rural areas), it was found that the most rational solution to this problem is the use of GSM / GPRS technologies. As a result of the conducted research the software component of the functional unit of measurement information exchange on GSM / GPRS technology with use of AT-commands which in the form of the block diagram of algorithm is given in Figure 10.

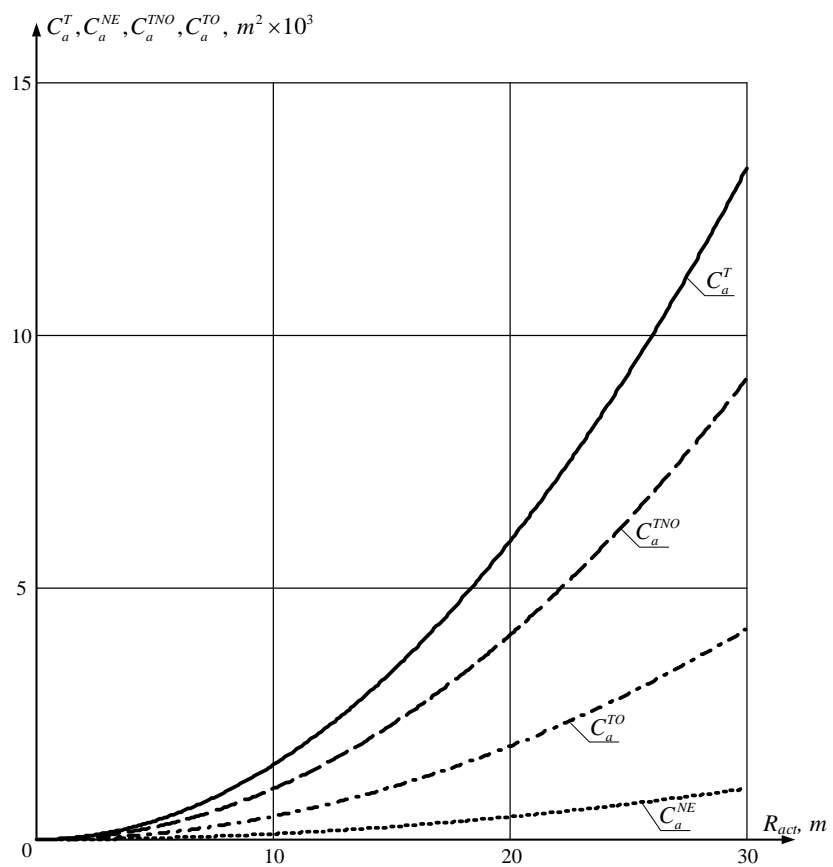

Figure 9. Quality indicators of wireless information exchange in greenhouses
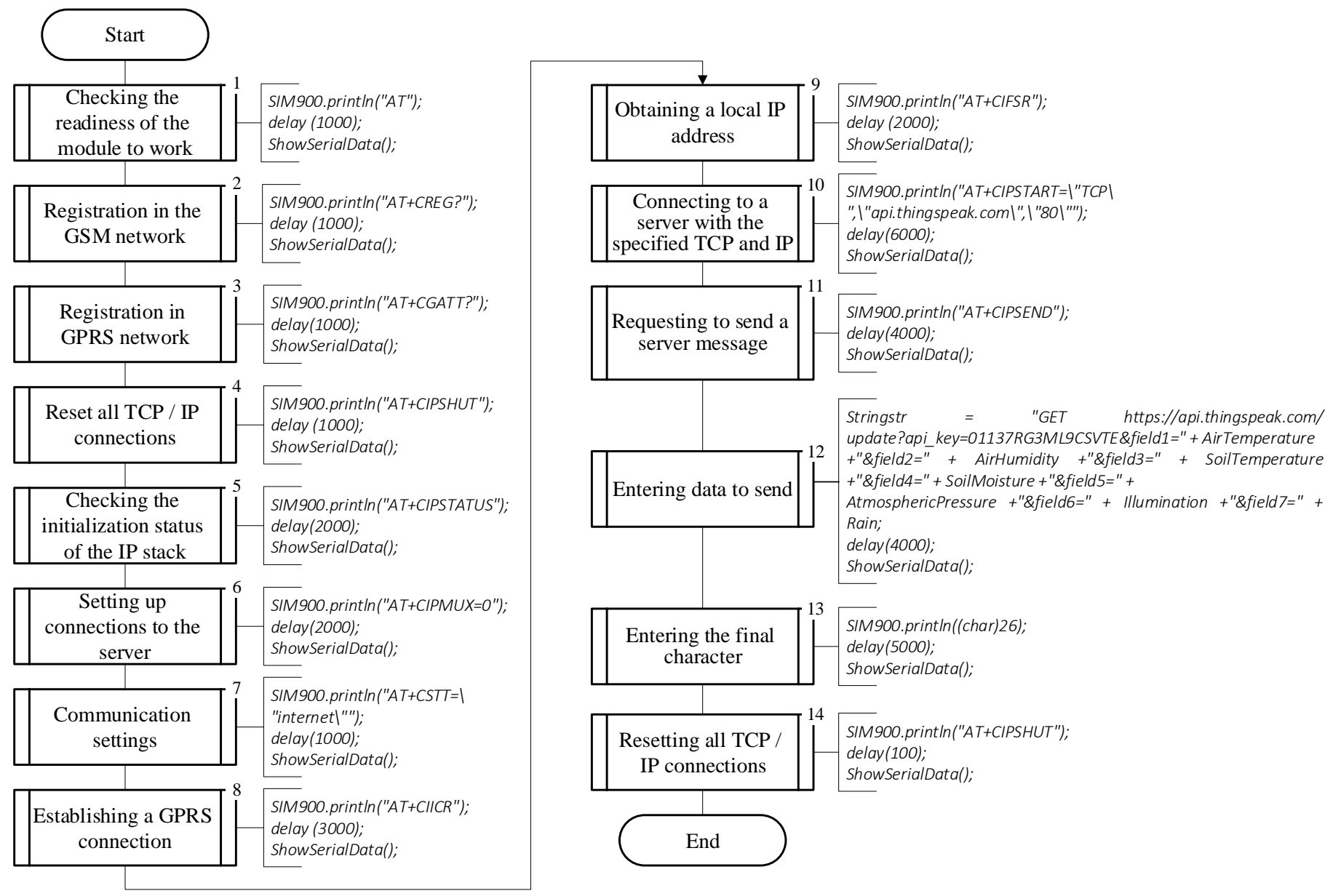

Figure 10. Block diagram of the algorithm of the software component of information exchange by GPRS / GSM 
3.2 Algorithmic means of transmission and processing of measurement information

During laboratory tests of the implemented information model of wireless monitoring of the greenhouse microclimate, a number of systemic shortcomings were identified, which are summarized as follows:

- typical error 1: analogue sensors of soil and climatic parameters are characterized by gross uncertainties in observation results, the appearance of which is due to the instability of the ADC reference power supply, which leads to significant distortion of measurement results and, consequently, erroneous operation of control systems;

- typical error 2 (see Figures 11 and 12): for digital sensors using 1-Wire and $\mathrm{I}^{2} \mathrm{C}$ technologies, the values of Inf (infinity) and $\mathrm{NaN}$ (no value) are typical in observation results, which during further statistical processing are the final results of measurement monitoring;

- typical error 3 (see Figure 13): when using standard libraries to work with digital sensors that work in conjunction with functional modules of information exchange, there is lack of time synchronization of internal interrupts, which distorts the modes of computer-integrated technology online.

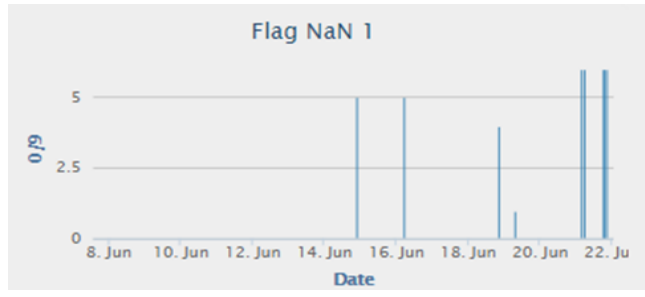

a) system errors in observation results Flag NaN 2

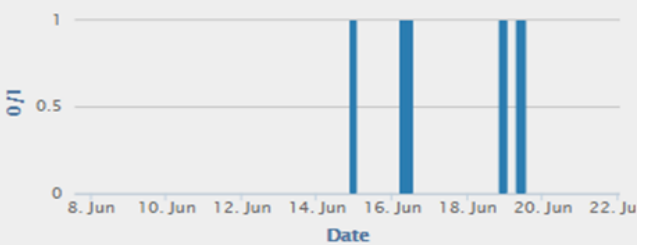

b) system errors in measurement results

Figure 11. Dynamics of system errors (Inf and NaN) before using the checking procedure

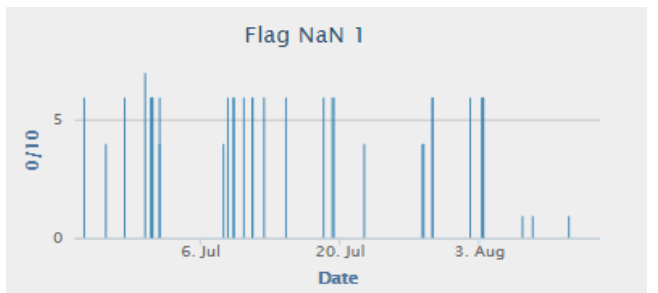

a) system errors in observation results Flag NaN 2

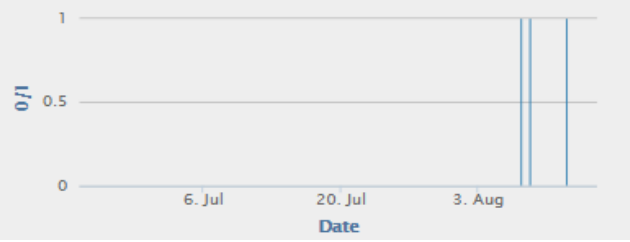

b) system errors in measurement results

Figure 12. Dynamics of system errors (Inf and $\mathrm{NaN}$ ) after the implementation of the checking procedure

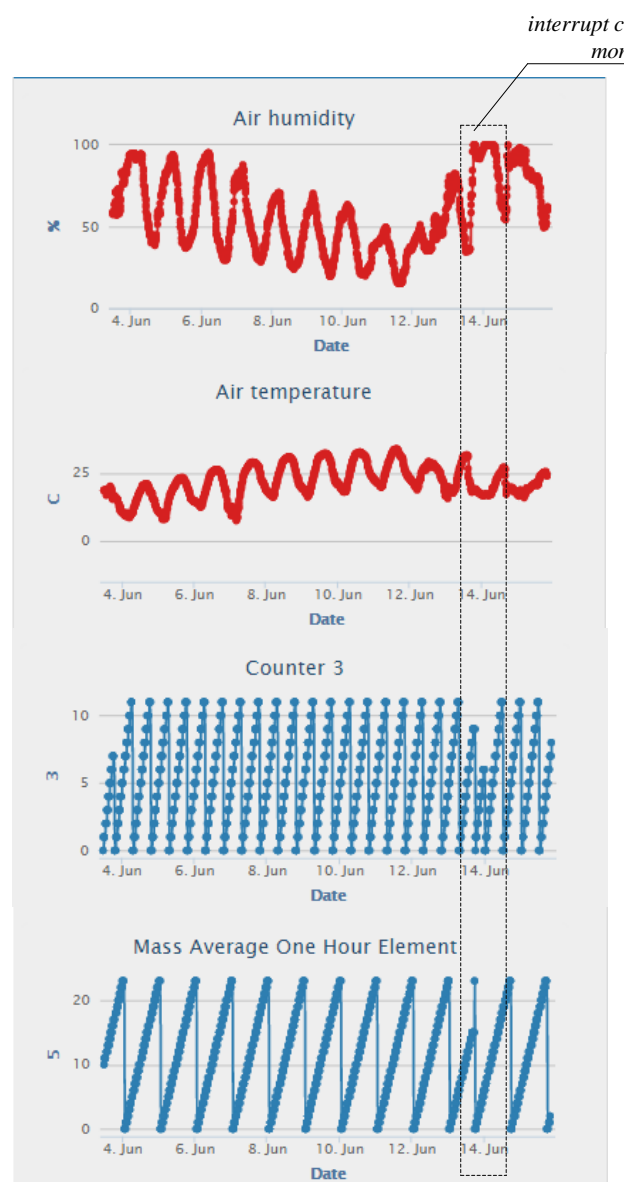

Figure 13. Graphical interpretation of mode distortions of the computer-integrated technology

To solve typical error 1, a hybrid median filtering algorithm of the $\alpha$-truncated filter type was used for the observation results obtained using analogue sensors. This algorithm assumes accumulation, ranking in ascending order arrays of observation results and their subsequent averaging [27].

$$
\left\{\begin{array}{l}
W_{\text {soil }}=\frac{1}{N_{1}-2 \alpha_{1}^{\text {filter }} N_{1}} \sum_{i=\alpha_{1} \cdot N_{1}+1}^{N_{1}-\alpha_{1} \cdot N_{1}} M e\left(W_{\text {soil }}\right) \\
v_{\text {air in }}=\frac{1}{N_{2}-2 \alpha_{2}^{\text {filter }} N_{2}} \sum_{i=\alpha_{2} \cdot N_{2}+1}^{N_{2}-\alpha_{2} \cdot N_{2}} M e\left(v_{\text {air in }}\right) \\
C_{C O 2 \text { in }}=\frac{1}{N_{3}-2 \alpha_{i}^{\text {filter }} N_{3}} \sum_{i=\alpha_{3} \cdot N_{3}+1}^{N_{3}-\alpha_{3} \cdot N_{3}} M e\left(C_{C O 2 i_{i}}\right) ; \\
p H_{\text {water }}=\frac{1}{N_{4}-2 \alpha_{4}^{\text {filter }} N_{4}} \sum_{i=\alpha_{4} \cdot N_{4}+1}^{N_{4}-\alpha_{4} \cdot N_{4}} M e\left(p H_{\text {water }_{i}}\right) ; \\
E C_{\text {water }}=\frac{1}{N_{5}-2 \alpha_{5}^{\text {filter }} N_{5}} \sum_{i=\alpha_{5} \cdot N_{5}+1}^{N_{5}-\alpha_{5} \cdot N_{5}} M e\left(E C_{\text {water }}\right) ; \\
O P R_{\text {water }}=\frac{1}{N_{6}-2 \alpha_{6}^{\text {filter }} N_{6}} \sum_{i=\alpha_{6} \cdot N_{6}+1}^{N_{6}-\alpha_{6} \cdot N_{6}} M e\left(O P R_{\text {water }}\right)
\end{array}, ;\right.
$$

where, $N_{1}, N_{2}, N_{3}, N_{4}, N_{5}, N_{6}$ - number of elements in the corresponding samples of observation results; $\mathrm{Me}\left(W_{\text {soil }}\right)$, $\operatorname{Me}\left(v_{\text {air in }}\right), \operatorname{Me}\left(C_{C O 2 i_{i}}\right), \operatorname{Me}\left(p H_{\text {water }_{i}}\right), \operatorname{Me}\left(E C_{\text {water }_{i}}\right)$, $M e\left(O P R_{\text {water }_{i}}\right)$ - ranked in ascending order arrays of observation results; $\alpha_{i}^{\text {flter }}=\frac{2}{N_{i}+1}-$ parameter of the averaging 
algorithm.

To solve typical error 2 in the algorithmic software component of the studied computer-integrated technology, there is a procedure for checking the presence and in case of their occurrence, excluding the observation results that contain the values of Inf and $\mathrm{NaN}$. As can be seen from the analysis of the results shown in Figures 11 and 12, the probability of Inf and $\mathrm{NaN}$ values in the observations is from $0.6 \%$ to $1.1 \%$. Prior to using the Inf and $\mathrm{NaN}$ checking procedure, the probability of such values appearing in the measurement results was equal to the probability of their occurrence in the observation results. After using the procedure for checking the presence of Inf and NaN, the probability of such values in the measurement results decreased to $0.01 \%$, which confirms the effectiveness of the proposed procedure for checking the presence of Inf and $\mathrm{NaN}$ values in the first iteration of averaging observations.

In order to eliminate typical error 3 in the algorithm of the investigated information model, the forced permission / prohibition of interrupts is provided when performing the procedure for polling the sensors. In order to increase the reliability of the system, the procedure for restoring the realtime mode by checking the occurrence of such a mode, reading from the flash drive and restoring the values of the variables responsible for the running time is provided in the operating algorithm. Therefore, taking into account detection and exclusion of typical errors in the work of the studied computerintegrated technology, an algorithm was developed to increase the reliability of transmission and processing of measurement information, which is shown in Figure 14.

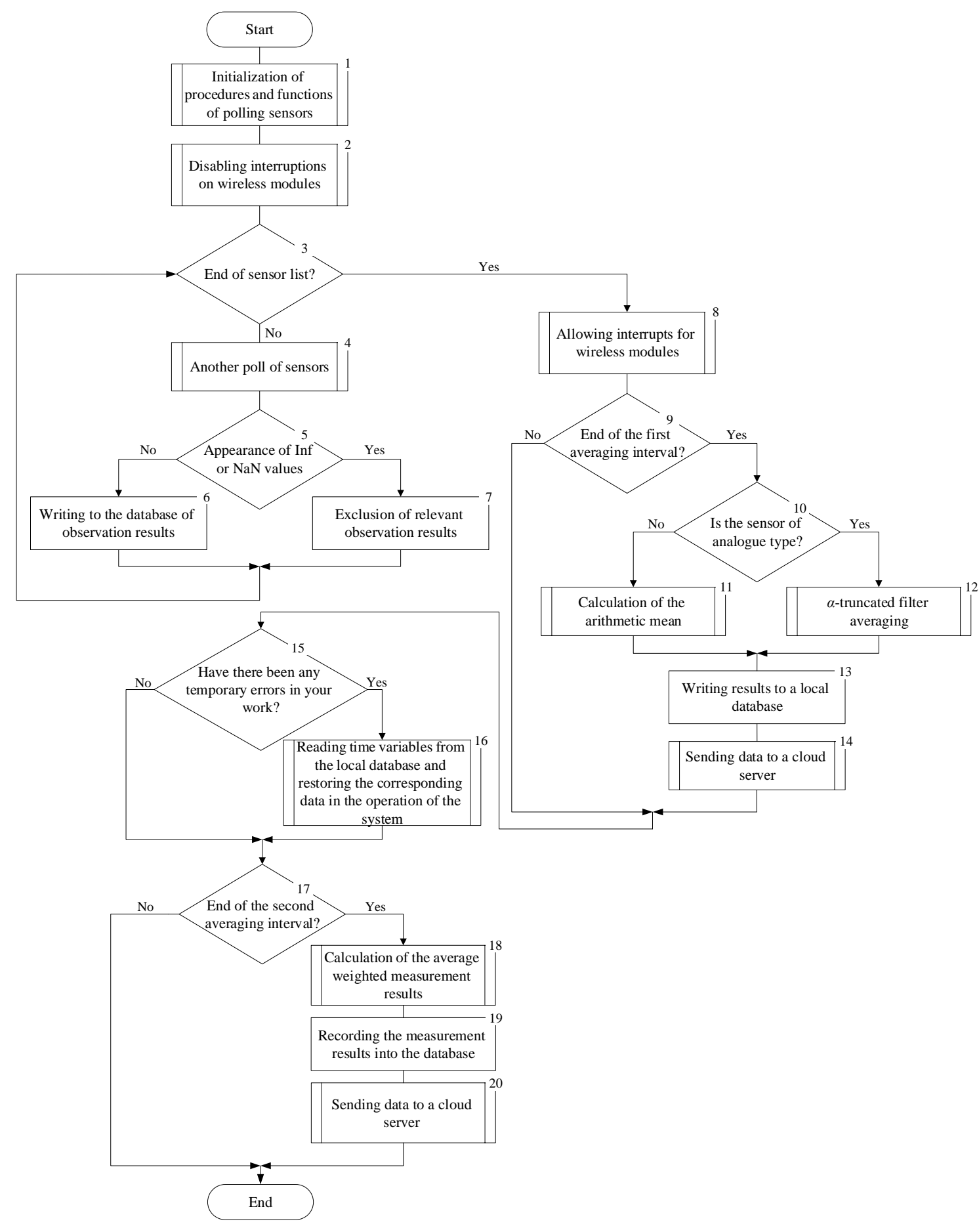

Figure 14. Block diagram of the algorithm for increasing the reliability of transmission and processing of information 
Figure 14 shows a block diagram of the algorithm of one iteration of the proposed methods to improve the accuracy of processing and reliability of transmission of measurement information. Such procedures and functions, which form the algorithmic basis of the developed information model, are performed in the main subprogram of the computer-integrated technology for monitoring the state of the greenhouse microclimate an infinite number of times before the forced stop. In order to increase the ergonomics of visualization and operational analysis of the results, data averaging is carried out in two stages in the microcontroller unit of the system and at the third stage on the cloud server. The first time interval is 10 minutes and is performed according to the methods of $\alpha$ truncated filter for analogue and arithmetic mean for digital sensors. The second time the interval is 1 hour and averaging is performed according to the weighted average method. Also, the use of the ThingSpeak IoT Analytics ${ }^{\circledR}$ cloud service allows performing a posteriori statistical analysis of monitoring results at the third stage of averaging.

\section{DISCUSSION AND SUGGESTIONS FOR FUTURE INVESTIGATIONS}

The main scientific and applied effect of the obtained results is developing the theory of creating information models of aggregation, wireless exchange and intellectualized interpretation of the computerized observation results of the integrated state of the microclimate of industrial greenhouse agricultural production. The main priority areas of further research are: long-term testing of the proposed technology in real operating conditions; algorithmization of the obtained information model at the level of industrial logic controllers of greenhouse production automation complexes; assessment of investment attractiveness of the received scientific and technical decisions.

\section{CONCLUSIONS}

The article solves the topical problem of developing scientific and applied bases for the synthesis of information models of computer-integrated systems for monitoring the microclimate of agricultural greenhouses, which will increase the efficiency of greenhouse cultivation by modernizing the software and hardware base of agricultural production. The main results of the article are:

- bibliographic review, critical analysis and logical generalization of the known scientific results in computerintegrated and infocommunication technologies in the field of vegetable growing in greenhouses with further determining of research areas;

- synthesis of structural and algorithmic organization and implementation of software and hardware of computerintegrated technology for monitoring the state of the greenhouse microclimate;

- development and testing of the computer model of the process of wireless exchange of measurement information;

- development and software implementation of algorithmic provision for the information model of computer-integrated technology for greenhouse microclimate monitoring, which allowed increasing functional reliability of wireless transmission and aggregation of measurement results;

- substantiation of the set of promising areas of further research to improve the software and hardware base of agricultural production.

\section{REFERENCES}

[1] FAOSTAT. Food and agriculture organization of the united nations. http://www.fao.org/faostat/en/\#home, accessed on Oct. 25, 2021.

[2] Baudoin, W., Nersisyan, A., Shamilov, A., Hodder, A., Gutierrez, D. (2017). Good agricultural practices for greenhouse vegetable production in the South East European countries. Food and Agriculture Organization of the United Nations. https://www.fao.org/3/i6787en/I6787EN.pdf.

[3] American Society of Agricultural and Biological Engineers ANSI/ASAE EP406.4 JAN2003 (R2008) Heating, Ventilating and Cooling Greenhouses. http://materialstandard.com/wpcontent/uploads/2019/07/ANSI-ASABE-EP406-4JAN2003-R2008.pdf, accessed on Oct. 15, 2021.

[4] Laktionov, I.S., Vovna, O.V., Bashkov, Y.O., Zori, A.A., Lebediev, V.A. (2019). Improved computer-oriented method for processing of measurement information on greenhouse microclimate. Int. J. Bioautomation, 23(1): 71-86. https://doi.org/10.7546/ijba.2019.23.1.71-86

[5] Both, A.J., Benjamin, L., Franklin, J., Holroyd, G., Incoll, L.D., Lefsrud, M.G., Pitkin, G. (2015). Guidelines for measuring and reporting environmental parameters for experiments in greenhouses. Plant Methods, 11(43): 1-18. https://doi.org/10.1186/s13007-015-0083-5

[6] Laktionov, I., Vovna, O., Bondarenko, V., Zori, A., Lebediev, V. (2020). Rationale for the structural and algorithmic organization of a computerized monitoring and control system for greenhouse microclimate using the scale transformation method. Int. J. Bioautomation, 24(1): 51-64. https://doi.org/10.7546/ijba.2020.24.1.000612

[7] Laktionov, I.S., Vovna, O.V., Kabanets, M.M., Derzhevetska, M.A., Zori, A.A. (2020). Mathematical model of measuring monitoring and temperature control of growing vegetables in greenhouses. International Journal of Design \& Nature and Ecodynamics, 15(3): 325-336. https://doi.org/10.18280/ijdne.150306

[8] Kamilaris, A. (2018). A review on the application of natural computing in environmental informatics. In: $32^{\text {nd }}$ Enviro. Info, Munchen, pp. 1-11. https://arxiv.org/abs/1808.00260.

[9] Erazo-Rodas, M., Sandoval-Moreno, M., MunozRomero, S., Huerta, M., Rivas-Lalaleo, D., Naranjo, C., Rojo-Alvarez, J. (2018). Multiparametric monitoring in equatorian tomato greenhouses (I): Wireless sensor network benchmarking. Sensors, 18(8): 2555. https://doi.org/10.3390/s18082555

[10] Laktionov, I., Vovna, O., Zori, A. (2017). Copncept of low cost computerized measuring system for microclimate parameters of greenhouses. Bulg. Journal of Agric. Sc., 23(4): 668-673. https://www.agrojournal.org/23/04-24.pdf.

[11] Khedo, K.K., Hosseny, M.R., Toonah, M.Z. (2014). PotatoSense: A wireless sensor network system for precision agriculture. In: Proceedings of the IST-Africa Conference, Mauritius, pp. 1-11. https://doi.org/10.1109/ISTAFRICA.2014.6880613 
[12] Sun, D.Z., Jiang, S., Wang, W.X., Tang, J. (2010). WSN design and implementation in a tea plantation for drought monitoring. In: Proceedings of the International Conference on Cyber-Enabled Distributed Computing and Knowledge Discovery (CyberC), Huangshan, pp. 156-159. https://doi.org/10.1109/CyberC.2010.36

[13] Aquino-Santos, R., Gonzalez-Potes, A., Edwards-Block, A., Virgen-Ortiz, R.A. (2011). Developing a new wireless sensor network platform and its application in precision agriculture. Sensors, 11(1): 1192-1211. https://doi.org/10.3390/s110101192

[14] Kumar, S., Chauhan, S. (2011). A survey on scheduling algorithms for wireless sensor networks. Int. Journal of Computer Applications, 20(5): 7-13. https://doi.org/10.5120/2432-3271

[15] Jørgensen, M.H. (2018). Agricultural field production in an 'Industry 4.0' concept. Agronomy Research, 16(1): 94-102. http://dx.doi.org/10.15159/ar.18.007

[16] Majety, V.D., Murali, G. (2018). A remote epileptic patient supervising system. Advances in Modelling and $\begin{array}{llll}\text { Analysis } & \mathrm{B}, & 61(4): & \text { 207-210. }\end{array}$ https://doi.org/10.18280/ama_b.610405

[17] Cannistraro, M., Restivo, R. (2018). Monitoring of indoor microclimatic conditions of an eighteenth-century church, with wireless sensors. Advances in Modelling and Analysis B, 61(1): 28-36. https://doi.org/10.18280/ama_b.610106

[18] Dilbaz, A.S. (2017). Design and implementation of a smart greenhouse. Master of Science Thesis, the Graduate School of Natural and Applied Sciences of Middle East Technical University, Ankara. http://etd.lib.metu.edu.tr/upload/12621619/index.pdf.

[19] Abdullah, A., Enazi, S.A., Damaj, I. (2016). Agrisys: A smart and ubiquitous controlled-environment agriculture system. In: $3^{\text {rd }}$ MEC International Conference on Big Data and Smart City, Muscat, pp. 1-6. https://doi.org/10.1109/ICBDSC.2016.7460386

[20] Kavianand, G., Nivas, V.M., Kiruthika, R., Lalitha, S. (2016). Smart drip irrigation system for sustainable agriculture. In: 2016 IEEE Technological Innovations in ICT for Agriculture and Rural Development (TIAR), Chennai, pp.

19-22. https://doi.org/10.1109/TIAR.2016.7801206

[21] Li, Z., Wang, J., Higgs, R., Zhou, L., Yuan, W. (2017). Design of an intelligent management system for agricultural greenhouses based on the Internet of Things. In: 2017 IEEE International Conference on Computational Science and Engineering (CSE) and IEEE International Conference on Embedded and Ubiquitous Computing (EUC), Guangzhou, pp. 154-160. https://doi.org/10.1109/CSE-EUC.2017.212

[22] Nandurkar, S.R., Thool, V.R., Thool, R.C. (2014). Design and development of precision agriculture system using wireless sensor network. In: 2014 First International Conference on Automation, Control, Energy and Systems (ACES), Hooghly, pp. 1-6. https://doi.org/10.1109/ACES.2014.6808017

[23] Teslyuk, T., Denysyuk, P., Kernytskyy, A., Teslyuk, V. (2015). Automated control system for arduino and android based intelligent greenhouse. In: 2015 XI Int. Conference on Perspective Technologies and Methods in MEMS Design, Lviv-Polyana, pp. 7-10. https://ieeexplore.ieee.org/document/7299440.
[24] Zhao, X.Y., Zheng, X.Y., Chen, D., Chen, Z.H., Sang, S.M., Zhang, Z.H. (2013). The design and implementation of the greenhouse monitoring system based on GSM and RF technologies. In: 2013 International Conference on Computational ProblemSolving (ICCP), Jiuzhai, pp. 32-35. https://doi.org/10.1109/ICCPS.2013.6893574

[25] Wu, Y., Li, X., Liu, Y., Lou, W. (2010). Energy-efficient wake-up scheduling for data collection and aggregation. IEEE Transaction on Parallel and Distributed System, 21(2): 275-287. https://doi.org/10.1109/TPDS.2009.45

[26] Kaiwartya, O., Abdullah, A.H., Cao, Y., Raw, R.S., Kumar, S., Liu, X., Shah, R.R. (2016). T-MQM: Testbed based Multi-metric Quality Measurement of Sensor Deployment for Precision Agriculture-A Case Study. IEEE Sensors Journal, 16(23): 8649-8664. https://doi.org/10.1109/JSEN.2016.2614748

[27] Alam, M., Rohac, J. (2015). Adaptive data filtering of inertial sensors with variable bandwidth. Sensors, 15(2): 3282-3298. https://doi.org/10.3390/s150203282

\section{NOMENCLATURE}

\section{Legend of symbols}

$C_{a c t}^{\mathrm{CO} 2 \text { in }}$
$C_{a c t}^{\mathrm{CO} 2 \text { out }}$
$C_{a}^{E}$
$C_{a}^{T}$
$C_{a}^{N E}$
$C_{a}^{T N O}$
$C_{a}^{T O}$
$D_{a c t}^{\text {air out }}$
$E_{a c t}^{\text {e in }}$
$E_{\text {act }}^{e \text { out }}$
$E C_{\text {act }}^{\text {water }}$

result of monitoring of carbon dioxide concentration in the growing area, ppm result of monitoring of carbon dioxide concentration in the environment, ppm effective coverage area, $\mathrm{m}^{2}$ total coverage area, $\mathrm{m}^{2}$

net (covered by only one group) effective coverage area, $\mathrm{m}^{2}$ total non-overlapping coverage area, $\mathrm{m}^{2}$ total overlapping coverage area, $\mathrm{m}^{2}$ result of instrumental monitoring of air direction in the environment result of instrumental monitoring of energy illumination in the greenhouse growing zone, $\mathrm{W} \cdot \mathrm{m}^{-2}$ result of instrumental monitoring of energy illumination in the environment, $\mathrm{W} \cdot \mathrm{m}^{-2}$

$E C_{a c t}^{\text {water }} \quad$ result of instrumental monitoring of electrical conductivity of the irrigation solution, $\mathrm{Cm} \cdot \mathrm{cm}^{-1}$

Location $_{\text {opt }}$ target function of location optimization of groups of sensors and functional modules

$N_{i} \quad$ number of elements in the corresponding samples of observation results

$M e\left(X_{i}\right)$ ranked in ascending order arrays of observation results

$O P R_{a c t}^{\text {water }}$ result of instrumental monitoring of the redox potential of the irrigation solution, $\mathrm{mV}$

$p H_{\text {act }}^{\text {water }}$ result of instrumental monitoring of irrigation solution acidity, units

$R_{\text {act }} \quad$ range of information exchange devices, $\mathrm{m}$

$T_{\text {act }}^{\text {air in }} \quad$ result of instrumental monitoring of air temperature in the growing area, ${ }^{\circ} \mathrm{C}$

$T_{\text {act }}^{\text {air out }} \quad$ result of instrumental monitoring of ambient air temperature, ${ }^{\circ} \mathrm{C}$

$T_{\text {act }}^{\text {soil }} \quad$ result of monitoring of soil temperature, ${ }^{\circ} \mathrm{C}$ 
$T_{a c t}^{\text {water }} \quad$ result of instrumental monitoring of irrigation solution temperature, ${ }^{\circ} \mathrm{C}$

$v_{\text {act }}^{\text {air in }}$

$v_{\text {act }}^{\text {air out }}$

$W_{a c t}^{a i r}$ in

$W_{\text {act }}^{\text {air out }}$

$W_{\text {act }}^{\text {soil }}$ result of instrumental monitoring of air flow rate in the growing area, $\mathrm{m} \cdot \mathrm{s}^{-1}$

result of instrumental monitoring of air flow speed in the environment, $\mathrm{m} \cdot \mathrm{s}^{-1}$

result of instrumental monitoring of humidity in the growing area, \%

result of instrumental monitoring of ambient humidity, $\%$

result of instrumental monitoring of soil moisture, \%

\section{Greek symbols}

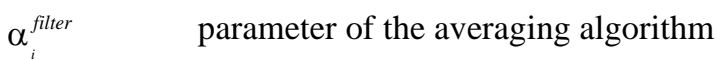

Subscripts

i

serial number of the sample of observations

Abbreviations

ADC analogue-to-digital conversion

IoT Internet of things

MC microcontroller

WSN wireless sensor network

ZC coordinating device

ZED end device

ZR routing device 